\title{
Explaining the effects of relative time in trace conditioning: A preliminary test of a comparator hypothesis
}

\author{
PETER S. KAPLAN \\ University of Colorado, Boulder, Colorado
}

\begin{abstract}
Scalar expectancy theory (SET) predicts that postacquisition manipulations of background expectancy should alter conditioned performance. An experiment was performed to test the application of this hypothesis to an explanation of the "temporal context" effect in trace conditioning. Pigeons were trained on an inhibitory trace conditioning procedure and then subjected to postacquisition manipulations of background expectancy. Nonreinforced exposure to the training apparatus eliminated conditioned withdrawal, exposure to USs under very long interreinforcer intervals slightly weakened conditioned withdrawal, and home-cage confinement had no effect on conditioned withdrawal. These results are discussed in terms of the predictions of SET and the role of background excitation in conditioned inhibition.
\end{abstract}

The conditioned performance of pigeons on trace autoshaping arrangements has been shown recently to depend upon the duration of the intertrial interval (ITI). Balsam (1984b) held constant the time between conditioned stimulus (CS) termination and unconditioned stimulus (US) onset (CS-US gap), and found faster acquisition of autoshaped keypecking with relatively long ITIs. Lucas, Deich, and Wasserman (1981) showed that unusually long CS-US gaps could be bridged when ITIs were very long. Kaplan (1984) extended these findings in a study of the ITI duration's effect on sign-tracking in trace conditioning. With CS-US gap duration fixed at $12 \mathrm{sec}$, conditioned approach to the CS developed when ITIs averaged $240 \mathrm{sec}$, no reliable conditioned responses (CRs) were acquired when ITIs averaged $60 \mathrm{sec}$, and conditioned withdrawal emerged when ITIs averaged $15 \mathrm{sec}$. Since conditioned withdrawal appears to be a good correlate of the CS's conditioned inhibitory power (see Bottjer, 1982; Hearst, Bottjer, \& Walker, 1980; Hearst \& Franklin, 1977; Kaplan \& Hearst, 1985; LoLordo \& Fairless, 1985; Miller \& Spear, 1985; Wasserman, Franklin, \& Hearst, 1974), it was concluded that a CS separated from US by a 12-sec gap could become a conditioned excitor, a conditioned inhibitor, or remain an apparently neutral stimulus, depending upon the "temporal context" in which periodic presentations of the CS and the US occurred. Trace conditioned performance seems to be the outcome of an interaction between at least two temporal parameters: CS-US gap and ITI durations.

Although several plausible explanations of these "tem-

This research was made possible by an NIMH postdoctoral traineeship. I thank David Thomas for generously supplying animals and equipment. Requests for reprints should be sent to Peter Kaplan at the Department of Psychology, Campus Box 345, University of Colorado, Boulder, CO 80309. poral context" effects can be advanced (see Kaplan, 1984; Konorski, 1948; Wagner, 1981; Wagner \& Larew, 1985), the present study was designed to test an explanation proposed by Balsam (1984b). His account represents an extension of scalar expectancy theory (SET) to situations in which the CS and US are not strictly contiguous in time. Briefly, SET asserts that Pavlovian conditioned performance is the outcome of a comparison between expectancy of the US during CS periods and expectancy of the US during the background (Gibbon, 1977; Gibbon \& Balsam, 1981; Jenkins, Barnes, \& Barrera, 1981). When expectancy during the CS represents a discriminable improvement over background expectancy, excitatory conditioned performance emerges.

In the version of SET designed to handle acquisition on standard delay autoshaping situations (Gibbon \& Balsam, 1981), the ratio comparator took the form: $\mathrm{C} / \mathrm{T}$, where $\mathrm{C}$ stands for cycle or background duration (average time between successive USs) and $T$ stands for trial or CS duration (average time between CS onset and US onset). Excitatory conditioned performance seems to emerge when the $\mathrm{C} / \mathrm{T}$ ratio is greater than approximately 2.5. Balsam (1984b) modified the ratio comparator rule to take into account the amount of time between CS onset and US onset that is actually filled by the CS. In standard delay conditioning, this entire interval is filled by the CS, but in trace conditioning only part of that interval is filled. On the basis of Kaplan's (1984) data, Balsam proposed that excitatory trace conditioning should develop with $\mathrm{C} / \mathrm{T}$ ratios of about 2.5 or more, and inhibitory trace conditioning should develop with $\mathrm{C} / \mathrm{T}$ ratios of about 1.5 or less. Informally, Balsam's model states that conditioned performance toward the CS does not reflect any "inherent" associative strength of the CS, but, rather, a comparison of expectancy during CS periods to overall background expectancy. The temporal context effect observed 
in trace conditioning can be explained simply by changes in background or cycle expectancy, which alter the outcome of the ratio comparator. Similarly, Balsam's model predicts that postacquisition manipulation of background strength should importantly affect $\mathrm{CS}$ responding. The present study was designed to test this prediction.

Three groups of pigeons were trained on a trace autoshaping procedure in which a 12 -sec green keylight CS was followed by an unfilled 12-sec gap before 3-sec access to grain. For all groups, ITIs averaged $15 \mathrm{sec}$, and so conditioned withdrawal should emerge according to Kaplan's (1984) findings. After 16 daily training sessions, CS presentations were discontinued and manipulations designed to alter background strength were begun. For one group, unsignaled USs were given, but the interreinforcer interval (IRI; time between onsets of successive USs) was $267 \mathrm{sec}$ as opposed to $42 \mathrm{sec}$ in the original training phase. The 267-sec IRI was chosen because Kaplan (1984) found that strong conditioned approach was obtained during original acquisition when that value was used in conjunction with a 12-sec CS-US gap. A second group received nonreinforced exposure to the training apparatus, a manipulation that should decrease contextual excitation to low levels. The remaining group served as home-cage controls; they were not placed in the apparatus at all during this phase. Following five sessions of these postacquisition manipulations, CS-alone tests were administered (in extinction), with the frequency of CS presentations equal to that in effect during the first phase.

If Balsam's (1984b) application of SET to trace conditioning is correct, then performance to the CS during the final test should be modulated by the manipulations done in Phase 2. Birds in the home-cage control group should continue to withdraw from the CS, since background strength should not have changed much during the five postacquisition days in which no exposure to CSs, USs, or the apparatus occurred. Birds given the unsignaled USs under the 267-sec IRI should now have a much lower background expectancy of the US, and therefore the quotient of the ratio comparator should be considerably higher. For example, if the birds learned that USs now came every $267 \mathrm{sec}$, and given Balsam's equation:

$$
r=C / T-G / T(C / T-1),
$$

where $\mathrm{G}=$ gap duration and $\mathrm{T}=$ the interval between CS onset and US onset, then the quotient should be equal to 6.063 , and birds would be expected to actually approach and peck the CS. Similarly, nonreinforced exposure to the apparatus should reduce background expectancy (cycle duration would approach infinity), and net approach and keypecking should be seen when the CS is retested.

No published studies report the effects of post-acquisition manipulations on trace conditioned performance. However, Kaplan and Hearst (1985) found that conditioned inhibitors, established via an explicitly unpaired procedure, lost their ability to elicit withdrawal behavior after nonreinforced exposure to the training apparatus. ${ }^{1}$ However, withdrawal was unaffected after (1) reinforced exposure to the training apparatus, (2) no interpolated exposure to the training apparatus, or (3) nonreinforced exposure to a novel apparatus. Furthermore, conditioned inhibitors that had lost their capacity to elicit conditioned withdrawal after nonreinforced exposure to the training apparatus immediately regained their capacity to do so after a few US or CS+ presentations. These findings have been interpreted by some as support for the comparator hypothesis (Balsam, 1984b; LoLordo \& Fairless, 1985; Miller \& Schachtman, 1985). The present study therefore also provided a chance to replicate Kaplan and Hearst's effect in a slightly different situation.

\section{METHOD}

\section{Subjects}

The subjects were 18 experimentally naive feral pigeons, maintained at $75 \%$ of their free-feeding weights. All birds had free access to grit and water, and were housed individually under a 12:12 light-dark cycle.

\section{Apparatus}

Two standard two-key conditioning chambers were housed in sound-attenuating enclosures. The left and right keys were dark, except during trials, at which time one or the other key could be illuminated by a miniprojector mounted behind it. Mixed grain was occasionally available for $3 \mathrm{sec}$ in an aperture located midway between the keys and $11 \mathrm{~cm}$ above the chamber floor. A white light illuminated the grain aperture when food was presented. A 2.8-W white houselight, located at the top center of the front panel, provided continuous illumination of the chamber. Extraneous noises were masked by a constant $75-\mathrm{dB}$ (SPL) white noise and by the sound of the chamber's ventilating system.

The location of the bird in the chamber (left or right side) was monitored by a microswitch beneath the teeter-totter floor (see Wasserman et al., 1974). A rough index of general activity was secured by counting the number of openings and closings of the microswitch. The number of keypecks during CS periods and the time a bird spent on the same side of the chamber as the illuminated key were recorded by conventional electromechanical relay circuitry located in an adjacent room.

\section{Procedure}

During magazine training, a pigeon was placed in its experimental chamber with the houselight on and the hopper was raised and filled with grain. After the bird had eaten for about $20 \mathrm{sec}$, the hopper was lowered. Subsequent grain presentations occurred irregularly for brief periods $(3-5 \mathrm{sec})$. Twenty grain presentations were given to each bird on a variable time (VT) 42 -sec schedule on Day 1, and another 20 were given on a VT 42-sec schedule on Day 2.

Conditioning began on the 3rd day. All animals were given 34 daily presentations of a $12-\mathrm{sec}$ green keylight followed by a 12-sec gap before 3-sec access to mixed grain. For all groups, the ITIs averaged $15 \mathrm{sec}$ (range: 10 to $20 \mathrm{sec}$ ). Sixteen sessions of this training took place on consecutive days. Beginning on the 17th day, and continuing for a total of 5 days, new contingencies were implemented. Three groups of birds were matched as closely as possible on approach-withdrawal behavior, keypecking, and general activity. One group (HC) merely sat in the home cage during this phase, where they were fed once each day to maintain their $75 \%$ weights. A second group (APP-) was given daily 90 -min exposures to the training apparatus without any CS or US presentation. A third group (APP+) received 20 daily US presentations, but under a 267 -sec IRI (range 180 to $320 \mathrm{sec}$ ). Session durations for these birds 
also averaged $90 \mathrm{~min}$. During this phase, general activity was recorded. On the day following the 5th exposure day, all birds were tested with 34 presentations of the 12-sec green keylight in extinction. These presentations occurred with the same frequency as they had during the original training phase (an average of $42 \mathrm{sec}$ between successive CS onsets).

Throughout the experiment, keylight presentations (when they occurred) were given on either the left or the right side of the chamber. The exact order of left and right presentations varied irregularly from trial to trial, with the constraints that (1) the key could not appear on the same side for more than three trials in a row, and (2) an equal number of left and right key illuminations occurred daily.

The total amount of time spent by a bird on the same side of the chamber as the illuminated key was recorded during each session, and this sum was divided by the total amount of time the keylight was on, to yield a performance measure known as the approachwithdrawal ratio. A ratio near 1.00 indicates strong approach toward the lit key, a ratio near 0.00 indicates strong withdrawal from the key, and a ratio near 0.50 indicates that the bird's location in the chamber is not systematically controlled by keylight location. Conditioned approach is an index of conditioned excitatory behavior and is usually accompanied by keypecking. Conditioned withdrawal appears to be a good correlate of the conditioned inhibitory status of the CS (Bottjer, 1982; Hearst et al., 1980; Hearst \& Franklin, 1977; Kaplan, 1984; Kaplan \& Hearst, 1985; Wasserman et al., 1974).

\section{RESULTS}

Figure 1 shows the acquisition of conditioned approachwithdrawal behavior for all 18 birds during Phase 1 . Birds acquired a reliable tendency to withdraw from the green keylight separated from the US by a 12 -sec gap, in replication of Kaplan's (1984) finding. An analysis of variance was carried out on the approach-withdrawal data for the three subgroups across the 16 days of Phase 1 . There was no significant effect of subgroups $[F(2,15)=$ 0.20 ], but there was a highly significant effect of trials $[F(15,225)=5.85, p<.001]$. The subgroups $\times$ trials interaction was not significant $[F(30,225)=0.50]$. A comparison of the mean approach-withdrawal ratio aver-

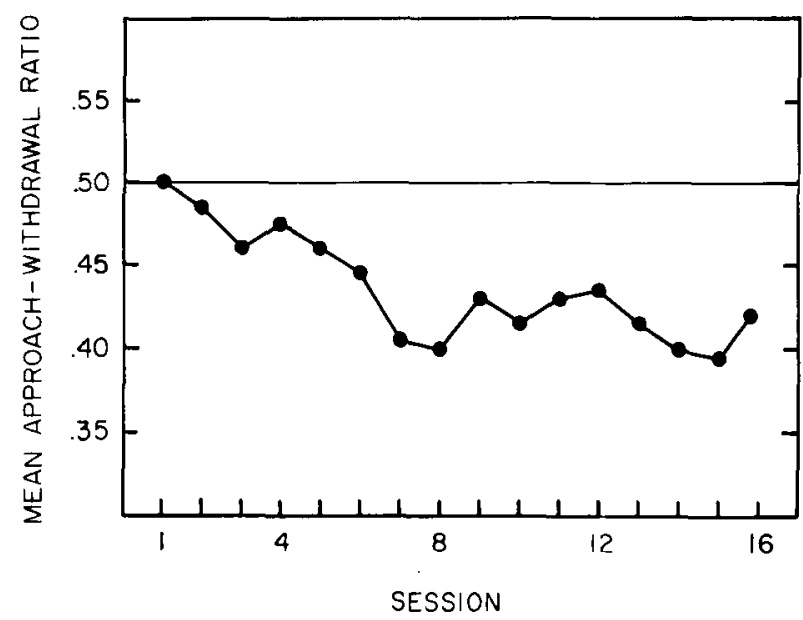

Figure 1. Mean approach-withdrawal ratios across the 16 acquisition sessions for birds trained on the inhibitory trace conditioning procedure.

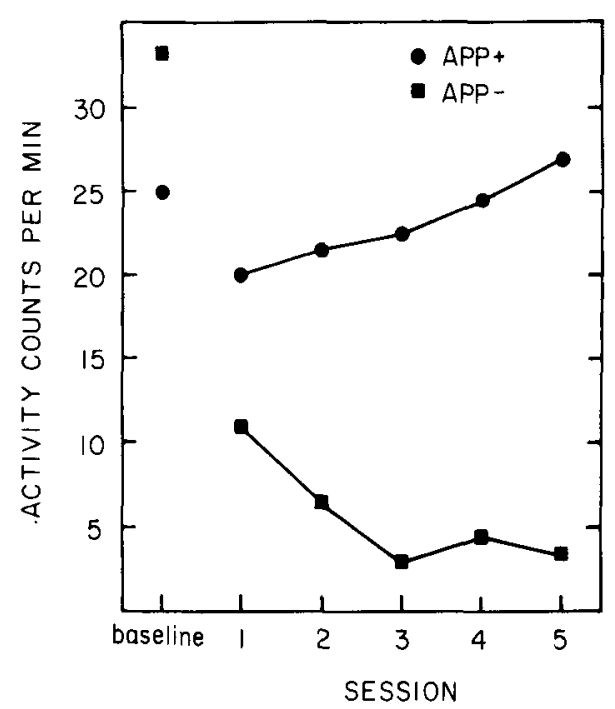

Figure 2. Mean number of activity counts per minute for birds in subgroups $A P P+$ and $A P P-$ on the final four acquisition sessions ("baseline") and the five sessions of Phase 2.

aged across all 18 subjects on Day 1 with that on Day 16 revealed a highly significant decrease $[t(17)=3.79, \mathrm{p}<$ .002]. Mean approach-withdrawal ratios deviated significantly from chance $(0.50)$ for the first time on Day 6 of acquisition $[\mathrm{t}(17)=2.79, \mathrm{p}<.02$, two-tailed], and continued to deviate significantly from chance on each acquisition day thereafter. Little or no keypecking occurred during this phase.

Since no CSs were presented during Phase 2 for any of the subgroups (HC, APP-, or APP+), obviously no approach-withdrawal data were recorded. However, an index of general activity in the conditioning chamber was obtained for the APP- and APP+ subgroups. Figure 2 shows the mean activity rate (counts/min) for each group averaged across the final four acquisition sessions ("baseline"), and for each of the 5 days of Phase 2. Across the final 4 days of acquisition, activity was slightly, but not significantly, higher in the APP-, relative to the APP+ subgroup $[t(10)=1.11, p>.20]$. Each bird in the APP - condition exhibited a large decrease in activity over the 5 days of Phase 2 . The means for these birds over the final four acquisition sessions, 1st day of Phase 2, and last day of Phase 2 were $34.7,10.8$, and 3.7, respectively; the change between the final four acquisition sessions and the final session of Phase 2 was highly significant $[t(5)=$ $7.50, \mathrm{p}<.001]$. Birds in the APP+ group exhibited a small net increase in activity over the 5 days of Phase 2. Their means over the final four acquisition sessions, 1st day of Phase 2 and last day of Phase 2 were 25.1, 20.3, and 32.1 , respectively. However, this trend was exhibited by only three of the six individual subjects; two birds exhibited decreases, and the other bird showed no change.

The results of the final extinction test, presented separately for the initial and final 16 test trials, are contained in Figure 3 for all three subgroups. Birds in the HC subgroup exhibited no significant change in the strength of 


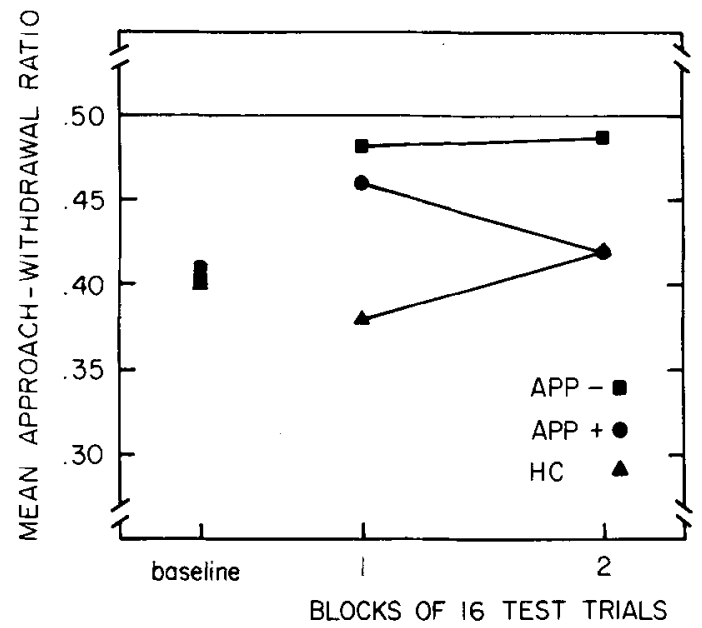

Figure 3. Mean approach-withdrawal ratios on the first 16 and last 16 test trials for birds in Subgroups HC, APP+, and APP-.

withdrawal behavior between the final four acquisition sessions and the first 16 test trials [0.40 vs. 0.40 ; $\mathfrak{t}(5)=0.60]$. Birds in the APP+ subgroup showed a significant weakening of withdrawal between the final 4 acquisition days and the first 16 test trials [0.41 vs. 0.46 ; $\mathfrak{t}(5)=4.84, p<.01]$. However, none of these animals exhibited conditioned approach or keypecking. Animals in the APP- subgroup also exhibited a significant weakening of withdrawal behavior $[0.40$ vs. $0.49 ; \mathrm{t}(5)=2.55$, $\mathrm{p}<.05$ ], but, again, none of these birds exhibited conditioned approach or keypecking. Although the approachwithdrawal ratios of all three subgroups were significantly below chance during the final four acquisition sessions ( $p<.05$, in each case), only the HC subgroup exhibited significant conditioned withdrawal during the first 16 test trials $[\mathrm{t}(5)=5.90, \mathrm{p}<.01$; each other $\mathrm{p}>.10]$.

Performance during the final 16 test trials for the $\mathrm{HC}$ and APP-birds paralleled their performance on the first 16 test trials, although $\mathrm{HC}$ birds began to exhibit weaker withdrawal. However, APP + birds exhibited significantly stronger withdrawal as testing progressed. Their approach-withdrawal ratios on the final 16 test trials were significantly lower than they had been on the initial 16 test trials $[t(5)=3.46, p<.02]$. Five of the six birds showed this trend. A comparison of approach-withdrawal ratios of these birds with chance $(.50)$ did not quite attain conventional levels of statistical significance during the second 16 test trials $[t(5)=2.07, .10>\mathrm{p}>.05]$.

\section{DISCUSSION}

Postacquisition manipulations designed to decrease levels of background excitation weakened the conditioned withdrawal of birds trained on an inhibitory trace conditioning procedure, but did not lead to conditioned approach or keypecking behavior. Therefore, separate alterations of background strength can, under certain cir- cumstances, affect subsequent peformance to the CS (cf. Kaplan \& Hearst, 1985), as one would predict if animals in some way "compared" CS and background expectancy. However, no strong support was obtained for the comparator hypothesis advanced by Balsam (1984b), since no approach and keypecking emerged during test sessions.

The elimination of conditioned withdrawal observed in the APP-condition replicates Kaplan and Hearst's (1985) finding that birds trained on an explicitly unpaired procedure failed to exhibit conditioned withdrawal after five sessions of nonreinforced exposure to training apparatus cues. However, Kaplan and Hearst (1985) found that birds trained initially on the explicitly unpaired procedure and then given home cage confinement, unsignaled USs under the same IRI that was in effect during acquisition, or nonreinforced exposure to novel apparatus cues continued to withdraw from the CS. Furthermore, for the cases in which withdrawal was eliminated, a few presentations of the US, or even a CS+ for food, immediately reinstated the withdrawal response. Kaplan and Hearst interpreted their effects in terms of a supportive role for background excitation in conditioned inhibition (inhibitors are thought to be "inactive" in the absence of some form of background excitation, supplied by either US or CS+ presentations). This interpretation is consistent with the notion that animals in some way compare CS and background expectancy or associative strength, and can also be applied to the current findings.

Although the APP - findings support some sort of comparator explanation, can they be said to support SET? The answer to this question depends on the success of the APP - manipulation. According to current thinking (Balsam, 1984a, 1985; Rescorla, Durlach, \& Grau, 1985), the significant decrease in activity in the APP-condition during nonreinforced exposure to the apparatus reflects a decrease in background expectation of the US (or extinction of the context-US association). The reduction of activity to very low levels during the second phase suggests that background expectation of the US was also reduced to very low levels. Were background extinction complete, the quotient of the $\mathrm{C} / \mathrm{T}$ ratio would approach infinity, and we would expect very strong excitatory performance. However, even if background extinction were not complete, the $\mathrm{C} / \mathrm{T}$ ratio should be quite high (since the value of $C$ would be very high) and excitatory performance should be evident. Since no excitatory performance emerged during the test, no support for a "strong" version of SET was obtained. However, it is conceivable that some evidence for excitation would have been obtained if indirect assays were applied (e.g., blocking or savings tests).

The elimination of withdrawal observed in the APPcondition might be attributed to competition between inactivity and conditioned withdrawal on the test day (inactivity persisted during the test day for these birds), rather than to any reduced background expectancy. This alternative cannot be definitely discounted here. However, 
Kaplan and Hearst (1985) were able to rule out this alternative in their related experiments. Birds trained on an inhibitory procedure and then given nonreinforced exposure to a novel apparatus exhibited strong withdrawal on the test day, even though they were as inactive as the group given nonreinforced exposure to the training apparatus during the interpolated session. Also, in Kaplan and Hearst's (1985) work, inactivity had no effect on performance directed toward conditioned excitors. Furthermore, eliminated withdrawal behavior could be rapidly reinstated by a few US or CS+ presentations, which suggests that US expectancy was more important than activity per se.

The APP+ manipulation led to a weakening of withdrawal behavior during the first block of 16 test trials, but that behavior recovered significantly during the second block of 16 test trials. Had only the initial effect been observed, one might argue that the manipulation had an effect in the direction predicted by SET. However, the recovery of withdrawal suggests that an alternative interpretation may be in order. Perhaps the disruption of conditioned withdrawal behavior during the first 16 test trials was due to competing responses acquired during the phase of unsignaled US deliveries, and withdrawal later recovered as these competing responses weakened during the extinction test. Alternatively, the recovery observed could be due to a reinstatement of background expectancy during the test due to the short cycle of stimulus events on the test day, which may have served as a retrieval cue for the active inhibitory status of the CS that existed during the acquisition phase (short cycles were in effect then, too).

One hundred presentations of unsignaled USs may have been insufficient to completely transform background expectancy to the desired low level in the APP+ group. Since no consistent activity changes were evident in the APP+ condition, no independent evidence exists to show that background expectancy of the US did indeed change. On the strength of previous work by Balsam and his associates (Balsam, 1984a; Balsam \& Schwartz, 1981), one would expect background values to change quickly. Unfortunately, conclusions derived from rate of context conditioning during original training may not apply to changes in contextual strength after acquisition has occurred.

Overall, these findings show that extinction of background cues leads to an elimination of the conditioned withdrawal behavior acquired on a trace conditioning arrangement-a finding consistent with the idea that some background expectancy of the US is necessary for the expression of conditioned inhibition (see Kaplan \& Hearst, 1985). In this sense, pigeons do compare CS and background expectancies. However, specific predictions of SET - particularly with regard to the emergence of conditioned approach and keypecking-found no support here (cf. LoLordo \& Fairless, 1985). Further research, employing different conditioning parameters (e.g., prolonged exposure to background manipulations) and measures of excitatory performance other than conditioned approach and keypecking (e.g., the CS's ability to block excitatory conditioning to an added cue), will be necessary before one concludes that SET fails entirely to explain trace conditioned performance. A modified version of Balsam's (1984b) model might also be proposed, in which initial background expectancy is not altered by separate manipulations of background expectancy following acquisition. Perhaps animals compare CS expectancy to the original value of the background, regardless of the US expectancy in the test context (but see Miller \& Schachtman, 1985, for contradictory evidence).

\section{REFERENCES}

Balsam, P. (1984a): Bringing the background into the foreground: The role of contextual cues in autoshaping. In $\mathbf{M}$. Commons, R. Herrnstein, \& A. Wagner (Eds.), Quantitative analyses of behavior: (Vol. 3). Acquisition. Cambridge, MA: Ballinger.

Balsam, P. (1984b). Relative time in trace conditioning. In J. Gibbon \& L. Allan (Eds.), Timing and time perception. New York: New York Academy of Sciences.

BALsAM, P. (1985). The functions of context in learning and performance. In P. Balsam \& A. Tomie (Eds.), Context and leaming. Hillsdale, NJ: Erlbaum.

Balsam, P., \& Schwartz, A. (1981). Rapid contextual conditioning in autoshaping. Joumal of Experimental Psychology: Animal Behavior Processes, 7, 382-393.

BotTJER, S. (1982). Conditioned approach and withdrawal behavior in pigeons: Effects of a novel extraneous stimulus during acquisition and extinction. Learning \& Motivation, 13, 44-67.

GiBbon, J. (1977). Scalar expectancy theory and Weber's law in animal timing. Psychological Review, 84, 279-325.

Gibbon, J., \& Balsam, P. (1981). Spreading association in time. In C. M. Locurto, H. Terrace, \& J. Gibbon (Eds.), Autoshaping and conditioning theory (pp. 219-253). New York: Academic Press.

Hearst, E., BotTJER, S., \& WalKer, E. (1980). Conditioned approachwithdrawal behavior and some signal-food relations in pigeons: Performance and positive vs. negative "associative strength." Bulletin of the Psychonomic Society, 16, 183-186.

Hearst, E., Franklin, S. (1977). Positive and negative relations between a signal and food: Approach-withdrawal to the signal. Journal of Experimental Psychology: Animal Behavior Processes, 3, 37-52.

Jenkins, H., Barnes, R., \& Barrera, F. (1981). Why autoshaping depends on trial spacing. In C. Locurto, H. Terrace, \& J. Gibbon (Eds.), Autoshaping and conditioning theory. New York: Academic Press.

KAPLAN, P. (1984). Importance of relative temporal parameters in trace autoshaping: From excitation to inhibition. Journal of Experimental Psychology: Animal Behavior Processes, 10, 113-126.

Kaplan, P., Hearst, E. (1985). Contextual control and excitatory vs. inhibitory learning: Sudies of extinction, reinstatement, and interference. In P. Balsam \& A. Tomie (Eds.), Context and leaming. Hillsdale, NJ: Erlbaum.

KoNORSKI, J. (1948). Conditioned reflexes and neuron organization. New York: Cambridge University Press.

LoLoRdo, V., \& FAIRLESS, J. (1985). Pavlovian conditioned inhibition. The literature since 1969. In R. Miller \& N. Spear (Eds.), Information processing in animals: Inhibition and contingencies. Hillsdale, NJ: Erlbaum.

Lucas, G. A., Deich, J. D., \& Wasserman, E. A. (1981). Trace autoshaping: Acquisition, maintenance, and path dependence at long trace intervals. Joumal of the Experimental Anatysis of Behavior, 36, 61-74.

Miller, R., SChachtman, T. (1985). Conditioning context as an associative baseline: Implications for the content of associations and the epiphenomenal nature of conditioned inhibition. In R. Miller \& N. Spear (Eds.), Information processing in animals: Conditioned inhibition. Hillsdale, NJ: Erlbaum.

Miller, R., \& SPEAR, N. (Eds.) (1985). Information processing in animals: Conditioned inhibition. Hillsdale, NJ: Erlbaum. 
Rescorla, R., Durlach, P., \& GraU, J. (1985). Contextual learning in Pavlovian conditioning. In P. Balsam \& A. Tomie (Eds.), Context and learning. Hillsdale, $\mathrm{NJ}$ : Erlbaum.

WAGNER, A. (1981). SOP: A model of automatic memory in animal behavior. In N. Spear \& R. Miller (Eds.), Information processing in animals: Memory mechanisms. Hillsdale, NJ: Erlbaum.

WAGNER, A., \& LAREW, M. (1985). Opponent processes and Pavlovian inhibition. In R. Miller \& N. Spear (Eds.), Information processing in animals: Conditioned inhibition. Hillsdale, NJ: Erlbaum.

Wasserman, E., Franklin, S., \& Hearst, E. (1974). Pavlovian appetitive contingencies and approach vs. withdrawal to conditioned stimuli in pigeons. Journal of Comparative \& Physiological Psychology, 86, 616-627.
NOTE

1. The interreinforcement intervals used by Kaplan and Hearst on their explicitly unpaired procedure averaged $148 \mathrm{sec}$ (range 43 to $226 \mathrm{sec}$ ), and the termination of the $10-\mathrm{sec}$ red-keylight CS never preceded the US by less than $43 \mathrm{sec}$. The procedure used in Phase 1 here could also be described as an explicitly unpaired procedure, although the mean IRI duration was very short $(42 \mathrm{sec})$. Of course, depending upon one's definition of a "pairing" (see Kaplan, 1984), any trace conditioning procedure could probably be described as an explicitly unpaired procedure. Balsam's (1984b) model might therefore be thought of as a version of SET relevant to explicitly unpaired procedures as well.

(Manuscript received April 5, 1985;

revision accepted for publication August 22, 1985.) 